\title{
The Choice of Sports Specialization On the Basis of Morphological and Functional Characteristics in The Underwater Sport
}

\author{
Redi Elena Vladimirovna ${ }^{1 \star}$, Tolstopyatov Igor Anatolevich ${ }^{2}$, Chuprova Elena Dmitrievna ${ }^{3,4}$, Konopleva Elena \\ Nikolaevna $^{5}$ \\ ${ }^{1}$ Senior Lecturer, Department of Theory of Physical Culture and Sports, Siberian State University of Science and Technology \\ named after Academician M.F. Reshetneva Krasnoyarsk, Russia \\ ${ }^{2}$ Professor, Dean of the Faculty of Physical Culture and Sports, Siberian State University of Science and Technology named after \\ academician M.F. Reshetneva, Krasnoyarsk, Russia \\ ${ }^{3}$ Associate professor, candidate of pedagogical sciences, Department of Theory of Physical Culture and Sports, Siberian State \\ University of Science and Technology named after Academician M.F. Reshetneva, Krasnoyarsk, Russia \\ ${ }^{4}$ Associate professor of the department of theoretical foundations and management of physical culture and tourism. Siberian \\ Federal University, Krasnoyarsk, Svobodny Ave. 79, 660041 \\ ${ }^{5}$ Associate professor, candidate of pedagogical sciences, Department of Theory of Physical Culture and Sports, Siberian State \\ University of Science and Technology named after Academician M.F. Reshetneva, Krasnoyarsk, Russia
}

\section{Asian Journal of Complementary and Alternative Medicine. Volume 09 Issue 1}

Published on: 27/01/2021

*Author for Correspondence: Redi Elena Vladimirovna, Senior Lecturer, Department of Theory of Physical Culture and Sports, Siberian State University of Science and Technology named after Academician M.F. Reshetneva Krasnoyarsk, Russia, E-mail: russlen90@mail.ru

Cite this article as: Vladimirovna RE, Anatolevich TI, Dmitrievna CE, Nikolaevna KE. The Choice of Sports Specialization On the Basis of Morphological and Functional Characteristics in The Underwater Sport. Asian Journal of Complementary and Alternative Medicine, Vol 9(1), 16-19:2021.

\begin{abstract}
Aim. To investigate morphological and functional characteristics of sportsmen-divers, specializing in swimming in the stayers, sprinters and subsea disciplines.

Materials and methods. The study involved submariners aged from 18 to 25 years ( 15 boys and 15 girls). Each athlete is a member of the national team of the Krasnoyarsk territory and has a sports title not lower than the master of sports of Russia. The following methods are used: the method of evaluating anthropometric indicators, the method of evaluating morphofunctional indicators, and the method of mathematical statistics.

Results. Submariners who specialize in Stayer disciplines fit the second morphofunctional type of physical development (MFTFR) (according To O. N. Moskovchenko [19]). These athletes are characterized by an athletic build, above average height and light weight. This makes it easier to overcome the surface of the water environment. Athletes-divers, specializing in the sprint and underwater subjects, is attributed to the third MPTP (for O. N. Moskovchenko [19] ). Swimmers have high indicators of length and body weight, which allows them to perform speed-power work at a high level.

Conclusion. The data obtained in the course of the research can serve as an effective pedagogical tool in the training of submariners. The relationship between sports specialization and morphofunctional characteristics serves as a scientific basis for organizing the training process. The dynamics of changes in morphofunctional parameters depending on the specialization provides an opportunity to justify the choice of underwater discipline, which allows you to predict the high result of the athlete and individualize the training process.
\end{abstract}

Keywords. swimmers, divers, training process, morphological and functional features, sports specialty.

\section{INTRODUCTION}

Scuba diving is a sport based on swimming, diving and diving with the use of special equipment, instruments, equipment and equipment [10]. The high level of achievements of athletes on the Russian and world stage places increased demands on the level of fitness due to an increase in the volume and intensity of physical activity [11]. However, the volume and intensity of the load cannot increase indefinitely, since the athlete will have 
an adaptive limit and the growth of results will stop [1]. This indicates the need to use innovative approaches in the training process. Morphotype is one of the indicators of individual characteristics of the body and its adaptive capabilities to physical exertion [4,5,7]. Sports experts and scientists have proved that taking into account morphofunctional characteristics contributes to achieving high results $[2,3,6,7,16,17,20,21]$. The authors of scientific papers that conducted research in various sports indicate the need to take into account the morphofunctional features of the body when planning physical activity and choosing a sports specialization $[8,9,12,13,14,15,18]$. However, the study of morphofunctional characteristics of the body in underwater sports is devoted to a small number of works, which determined the relevance of this study.

\section{MATERIAL AND METHODS}

During the study, the following methods were used: analysis of data from literature sources and methodological materials; method for evaluating anthropometric indicators (height, weight, chest circumference measurement); method for evaluating morphofunctional indicators (heart rate, systolic blood pressure (SBP), vital capacity of the lungs (VEL), minute blood volume (MOC)). The method of mathematical processing was used to ensure the reliability and validity of the research results. A correlation analysis of the relationship between athletic performance, body weight, height, and WEL was performed among sprinters, stayers, and athletes swimming underwater exercises. Mathematical processing of the results was carried out on a personal computer using Microsoft Word and Microsoft Excel programs. The study involved submariners aged 18 to 25 years ( 15 boys and 15 girls). All athletes are members of the national team of the Krasnoyarsk territory and have a sports title not lower than the master of sports of Russia.

\section{RESULTS}

At the present stage, the construction of the training process, taking into account individual anthropometric indicators, increases the reserve capabilities of the body, increasing its biological stability and system reliability. Taking into account that the morphological and functional characteristics of the sportsmen-submariners have not been studied, we decided to conduct a comparative analysis, summarizing the data obtained in the course of the study of the members of the national team of the Krasnoyarsk Territory, depending on gender and specialization (Table 1).

According to the results of the study, the following conclusion can be made: athletes specializing in Stayer distances can be attributed to the second morphofunctional type of physical
Table 1: Indicators of physical development of sportsmandiver depending on gender and specialization

\begin{tabular}{|c|c|c|}
\hline Indicators & Women & Men \\
\hline \multicolumn{3}{|c|}{ Sprinters } \\
\hline Height (body length) (cm) & $167-178$ & $168-194$ \\
\hline Weight (body weight) (kg) & $61-71$ & $66-92$ \\
\hline Chest circumference $(\mathrm{cm})$ & $77-80$ & $95-102$ \\
\hline Lung capacity (ml) & $3800-4200$ & $5000-6900$ \\
\hline Systolic blood pressure (mm.rt.st) & $110-115$ & $110-120$ \\
\hline heart rate (beats per minute) & $60-64$ & $60-63$ \\
\hline \multicolumn{3}{|l|}{ Stayers } \\
\hline Height (body length) (cm) & $166-177$ & $165-184$ \\
\hline Weight (body weight) (kg) & $56-67$ & $62-85$ \\
\hline Chest circumference $(\mathrm{cm})$ & $75-78$ & $90-95$ \\
\hline Lung capacity $(\mathrm{ml})$ & $3700-4600$ & $5000-7000$ \\
\hline Systolic blood pressure (mm.rt.st) & $115-120$ & $105-120$ \\
\hline heart rate (beats per minute) & $59-64$ & $55-60$ \\
\hline \multicolumn{3}{|l|}{ Diver } \\
\hline Height (body length) (cm) & $163-171$ & $171-189$ \\
\hline Weight (body weight) (kg) & $53-76$ & $79-95$ \\
\hline Chest circumference $(\mathrm{cm})$ & $83-87$ & $106-113$ \\
\hline Lung capacity $(\mathrm{ml})$ & $4300-5200$ & $6000-7900$ \\
\hline Systolic blood pressure (mm.rt.st) & $105-120$ & $110-120$ \\
\hline heart rate (beats per minute) & $60-64$ & $61-63$ \\
\hline
\end{tabular}

development (MFTFR), which is characterized by harmony, average values of anthropometric indicators in relation to age and gender standards without pronounced changes in morphofunctional indicators, satisfactory adaptation of the cardiovascular system (CVS) and morphofunctional indicators.

Submariners who specialize in sprinting distances and underwater exercises can be attributed to the third IFTFR, which is characterized by well-developed bone and muscle tissue, high and above average anthropometric parameters in relation to age and gender standards, and high adaptive capabilities of the CCC.

Athletes who specialize in swimming at Stayer distances are characterized by an athletic build, average height - above average and light weight. This makes it easier to overcome the surface of the water environment. Submariners and sprinters have the highest indicators of length and body weight, which is not unimportant when performing speed-power work.

The morphotype largely determines the functional capabilities of an athlete, which ultimately will be reflected in the predisposition to choose a specialization in a particular sport. The correlation between the morphofunctional parameters of submariners and their sports specialization is shown in Table 2. 
Table 2: Comparative analysis of the relationship between sports results and physical parameters of highly qualified submariners

\begin{tabular}{|c|c|c|}
\hline Anthropometric parameters & $\begin{array}{c}\text { Correlation } \\
\text { coefficient }\end{array}$ & $\begin{array}{c}\text { Correlation } \\
\text { coefficient }\end{array}$ \\
\hline Sprinters & Women & Men \\
\hline Height (body length) $(\mathrm{cm})$ & 0,32 & 0,43 \\
\hline Weight (body weight) $(\mathrm{kg})$ & 0,73 & 0,75 \\
\hline Lung capacity $(\mathrm{ml})$ & 0,51 & 0,63 \\
\hline Stayers & Women & Men \\
\hline Height (body length) $(\mathrm{cm})$ & 0,21 & 0,30 \\
\hline Weight (body weight) $(\mathrm{kg})$ & 0,54 & 0,51 \\
\hline Lung capacity $(\mathrm{ml})$ & 0,69 & 0,71 \\
\hline diver & Women & Men \\
\hline Height (body length) $(\mathrm{cm})$ & 0,30 & 0,29 \\
\hline Weight (body weight) $(\mathrm{kg})$ & 0,76 & 0,81 \\
\hline Lung capacity $(\mathrm{ml})$ & 0,75 & 0,78 \\
\hline
\end{tabular}

Note:

- $(r<0.30)$ - low degree of dependence;

- (r from 0.31 to 0.50) - weak degree of dependence;

- (r from 0.51 to 0.70) - average degree of dependence;

- (r from 0.71 to 0.80) - a good degree of dependence.

- (rfrom 0.81 to 0.90 and higher) - a strong degree of dependence.

From the analysis of table 2, it follows that a good degree of dependence on athletic performance among sprinters in men and women has a weight $(r=0.75$ and $r=0.73)$, the average for both men and women has a vital lung capacity indicator $(\mathrm{r}=0.63$, $\mathrm{r}=0.51)$. Weak correlation between men and women with height $(\mathrm{r}=0.43, \mathrm{r}=0.32)$. Among stayers, a good correlation among men has a VEL indicator $(r=0.71)$, while women have an average correlation with this indicator $(\mathrm{r}=0.69)$. The growth rate for both men and women has a low degree of dependence $(r=0.30, r=0.21)$. Weight in this specialization of underwater sports, for men and women, has an average degree of dependence $(r=0.51, r=0.54)$. Athletes who specialize in scuba diving have a strong relationship with weight in both men $(\mathrm{r}=0.81)$ and women $(\mathrm{r}=0.76)$. Also, a good relationship between men and women can be traced with VEL $(r=0.78, r=0.75)$. Low degree of correlation between men and women with growth indicators $(\mathrm{r}=0.29, \mathrm{r}=0.30)$.

\section{CONCLUSION}

High level of sports achievements, competition in the fight for the right to be the first require constant improvement of the quality, efficiency and individualization of the training process. The growth of achievements in underwater sports is largely determined by the constant improvement of training methods for qualified athletes.

Using data on morphofunctional characteristics, the coach can correctly determine the specialization for the athlete, which in the future, at the stage of sports improvement and the stage of higher sports skill, will allow individualizing training methods, on the basis of which to achieve the highest sports results. Taking into account individual anthropometric indicators and proper construction of the training process increases the reserve capacity of the body, increasing its biological stability and reliability of the system.

The established morphofunctional markers can be successfully used in determining specialization, as well as in sports selection and technical training of athletes.

\section{REFERENCES}

1. Wilmore JH (1997) Physiology of sports. DL Church.

2. Czuba M, Wilk R, Karpinski J, Chalimoniuk M, Zajac A, et al. (2017) Intermittent hypoxic training improves anaerobic performance in competitive swimmers when implemented into a direct competition mesocycle. Plos One 12: e0180380.

3. Tolstopyatov IA, Redi EV, Ivanitsky VV, Zakharova LV (2018) Analysis of Underwater Swimming World Record Gains Regularities (Finswimming).

4. Kononova EV (2015) Adaptation of children and youth to modern socio-economic conditions on the basis of healthy saving technologies. Abakan 13: 148-150.

5. Folland JP, Williams AG (2010) The adaptations to strength training: Morphological and neurological contributions to increased strength. Sports Med 37: 145-168.

6. Maksimov AL (2012) Features of the functional state in young men from Magadan, depending on the type of constitution 12: 25-30.

7. Martirosov G (1977) Major Contemporary issues in sports. Sports Science and Physical Education 2: 8-29.

8. Martirosov JG (1968) Morphofunctional organization and sports.

9. Moskovchenko ON (2005) The teleological approach to the selection and management of the training of Greco-Roman wrestlers at the stage of advanced specialization: Monograph. Ipc Kgtu 2005: 158.

10. Moskovchenko ON (2014) Underwater sports and diving: Study guide.

11. Moskovchenko ON (2019) World records in finswimming sport: Growth profiling analysis. Theory and Practice of Physical Culture 969: 70-72.

12. Mjasnikova TI (2016) Evaluation of the fitness of qualified swimmers-divers using standard loads of varying intensity. Ural Federal University the first President of Russia V.N. Yeltsin 2016: 267-272.

13. SimakovaAN (2016) Morphological and functional characteristics of gymnasts aged 8-14 years of the city of Krasnoyarsk/Abstract of the thesis of Candidate of Medical Sciences Simakova Lyudmila Nikolaevna. KGMA 2006: 27.

14. Tjo S (1997) Sports morphology of highly qualified weightlifters // Material konferencii 9-12 ijunja 1997g. Krasnoyarsk//Aktual'nye voprosy biomedic. 
15. Shumakov AV (1997) Control of the training process of wrestlers according to model characteristics. Physical culture education in Siberia 1: 82 .

16. Bendikova E (2014) Lifestyle, Physical and Sports Education and Heaith Benefits of Physical Activity. European Researcher 69: 343-348.

17. Cekovik N, Dordevic M, Stefanovic N (2013) Somatotype analysis of the first-year students of the faculty of sport and physical education in Nis. XVI Scientific Conference "FIC COMMUNICATION 2013" in physical education, sport and recreation and I International Scientific Conference 23: 369-376.

18. Gaurav V, Singh A (2014) Anthropometric characteristics of Indian volleyball players in relation to their performance level. Turkish Journal of Sport and Exercise 16: 87-89.
19. Moskovchenko O Ivanitsky V, Zakharova L, Tolstopyatov I, Tatiana K, et al. (2018) Morphofunctional markers of kinetic aptitude in a sport selection system. Journal of Physical Education and Sports 18: 670-676.

20. Moskovchenko O (2011) Psycho-Physiological Types of Adaptation in the Assessment of Professional and Sport Selection. Journal of Siberian Federal University. Humanities \& Social Sciences 9: 1288-1300.

21. Pordigalo L, Iermakov S, Potop V, Romanenko V, Boychenko N, et al. (2017) Special Aspects of Psychophysiological Reactions of Different Skillfulness Athletes, Practicing Martial Arts. Journal of Physical Education and Sport 17: 519-526. 